\title{
Review
}

Débora M. Portilho, Roger Persson and Nathalie Arhel*

\section{Role of non-motile microtubule-associated proteins in virus trafficking}

DOI 10.1515/bmc-2016-0018

Received June 21, 2016; accepted November 4, 2016

Abstract: Viruses are entirely dependent on their ability to infect a host cell in order to replicate. To reach their site of replication as rapidly and efficiently as possible following cell entry, many have evolved elaborate mechanisms to hijack the cellular transport machinery to propel themselves across the cytoplasm. Long-range movements have been shown to involve motor proteins along microtubules (MTs) and direct interactions between viral proteins and dynein and/or kinesin motors have been well described. Although less well-characterized, it is also becoming increasingly clear that non-motile microtubule-associated proteins (MAPs), including structural MAPs of the MAP1 and MAP2 families, and microtubule plus-end tracking proteins (+TIPs), can also promote viral trafficking in infected cells, by mediating interaction of viruses with filaments and/or motor proteins, and modulating filament stability. Here we review our current knowledge on nonmotile MAPs, their role in the regulation of cytoskeletal dynamics and in viral trafficking during the early steps of infection.

Keywords: microtubule-associated protein; trafficking; virus.

\section{Introduction}

Microtubules (MTs) are cytoskeletal filaments consisting of 13 protofilaments of $\alpha$ - and $\beta$-tubulin heterodimers arranged as polymeric cylinders. They are highly dynamic,

*Corresponding author: Nathalie Arhel, Centre d'Études d'Agents Pathogènes et Biotechologies pour la Santé (CPBS)-FRE 3689 CNRS, and Université de Montpellier, F-34293 Montpellier, France, e-mail: nathalie.arhel@cpbs.cnrs.fr

Débora M. Portilho: INSERM U941, University Institute of Hematology, Saint-Louis Hospital, F-75010 Paris, France; and BioAxial SAS, F-75014 Paris, France

Roger Persson: BioAxial SAS, F-75014 Paris, France continuously switching between phases of growth and shrinkage, referred to as dynamic instability (1). MTs are involved in a wide range of cellular functions, including cell morphology, division, motility, and organelle positioning, as well as in disease, such as neurodegenerative disease, infection and immunity. Once the MT filaments are formed by nucleation at the centrosome and elongated from the subunit pool, their stability and mechanical properties are often controlled by a set of proteins that bind along the polymer. These so-called microtubuleassociated proteins (MAPs, not to be confused with mitogen-activated proteins) are essential for the regulation of MT dynamics.

Several types of MAPs have been identified in eukaryotes, including MT motors, MT plus-end and minus-end tracking proteins (+ TIPs, - TIPs), centrosome-associated proteins and structural MAPs. MTs, motors and nonmotile MAPs together constitute a highly efficient and tightly regulated machinery that ensures the directed transport of cargo such as organelles, vesicles, protein complexes and mRNAs within cells. Viruses have evolved multiple ways of hijacking the cellular transport machinery to propel themselves through the cell, from their site of entry to their sites of replication and egress (2-7). In particular, viruses that replicate in the nucleus, such as adenoviruses $(8,9)$, retroviruses $(10,11)$, and herpes viruses $(12,13)$, use the MT network and associated motors to traffic within the cytoplasm either from the cell periphery to the center of the cell (dynein) or in the reverse direction (kinesins). The importance of molecular motors in viral transport is well established and has been reviewed elsewhere $(14,15)$. More intriguing and less clear is the role of non-motile MAPs in the movement of viruses along microtubular tracks. The aim of this review is to discuss our current understanding of non-motile MAP functions and how they support viral replication.

\section{Structural MAPs}

The structural MAPs are non-enzymatic proteins that bind along the length of MTs, enhancing the assembly and the 
stability of the polymer. They can be grouped into two types, based on sequence analysis. Type I MAPs include MAP1A, MAP1B and MAP1S $(16,17)$. MAP1A and MAP1B are large $(>300 \mathrm{kDa})$, filamentous molecules found predominantly in axons and dendrites, whereas the shorter MAP1S is ubiquitously expressed. All three MAP1 proteins are synthesized as polyprotein precursors that are subsequently cleaved into $\mathrm{N}$-terminal-derived heavy chain and C-terminal-derived light chain to generate multiprotein complexes of one heavy and multiple light chain subunits (18). The light chains generated by MAP1A (LC2) and MAP1B (LC1) are interchangeable and can interact with both MAP1A and MAP1B heavy chains. A third separately encoded light chain 3 subunit (LC3, $16 \mathrm{kDa}$ ) is also found in mature MAP1A and MAP1B (19). All three MAP1 light chains as well as the MAP1A and MAP1B heavy chains can bind directly to MTs (Figure 1). In addition to MT-binding activity, MAP1A and MAP1B can also bind to microfilaments (20-22), suggesting that they can regulate both MT and microfilament stability and constitute cross-bridges between both networks.

Type II mammalian MAPs consist of the neuronal proteins MAP2 and Tau, and the ubiquitous MAP4 (23). MAP2 is found only in dendrites, where it forms fibrous cross-bridges between MTs and is involved in organelle trafficking. Tau is abundant in neurons, where it promotes formation of axonal MTs, stabilizes and increases their rigidity and drives neurite outgrowth. Tau can also control intracellular trafficking by interfering with the attachment and detachment cycle of motors, particularly by reducing the attachment of kinesins to MTs $(24,25)$. Abnormalities in the tau protein are implicated in many neurodegenerative and psychiatric disorders. MAP4 performs many different functions in a range of cells and tissues, including regulation of MT dynamics in interphase, mitosis and meiosis, organization and transport of organelles and vesicles in interphase cells, and regulation of cell shape during differentiation $(26,27)$.

\section{Microtubule plus-end tracking proteins (+ TIPs)}

MT plus-end tracking proteins (+ TIPs) are a diverse group of evolutionarily conserved cellular factors that accumulate at the ends of growing MTs. They regulate different aspects of cell architecture by controlling MT dynamics, and interaction with cellular structures and proteins $(28,29)$. The first identified + TIP was cytoplasmic linker protein (CLIP)-170 (officially known as CLIP1) (30). Since then many different families of + TIPs have been identified, that can be classified on the basis of structural elements that mediate interaction with MTs and other + TIPs, with the common characteristic of specifically accumulating at MT plus ends (Figure 2). Minus-end

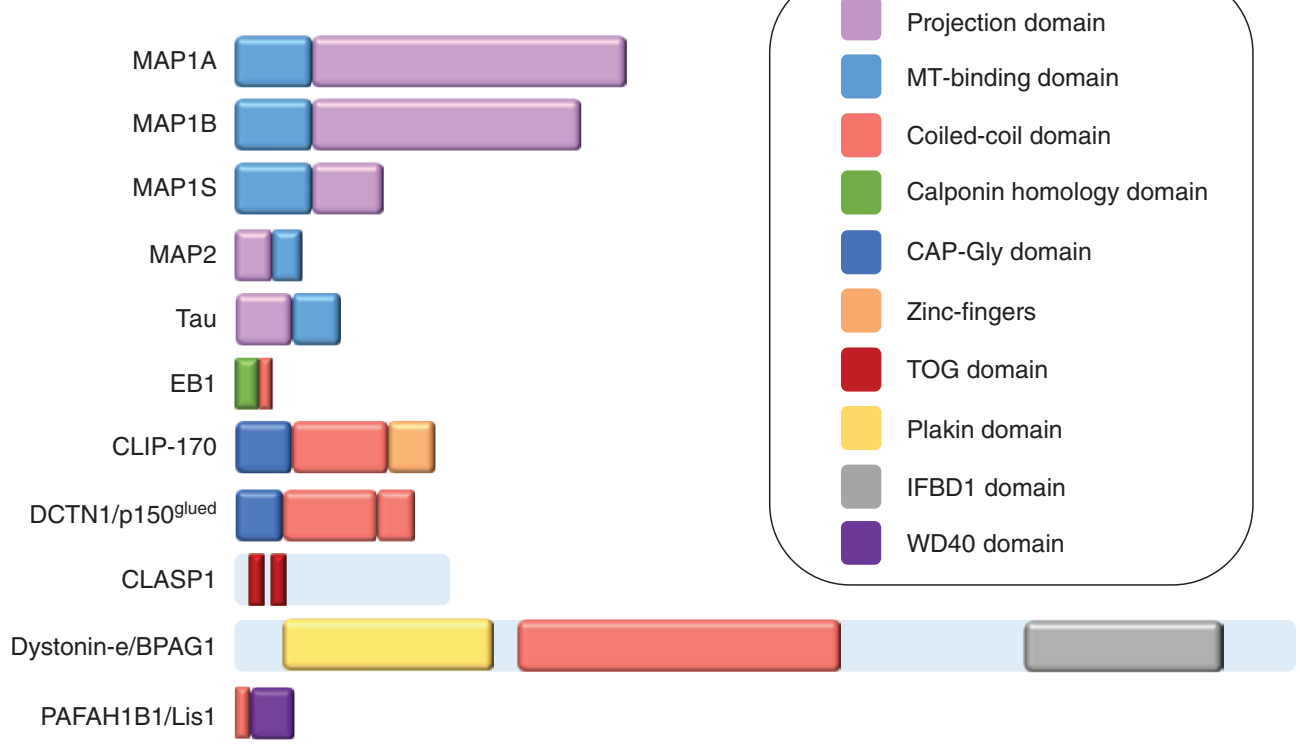

Figure 1: Examples of different MAPs and their functional domains.

Some MAPs, such as MAP2 and tau, exist as multiple alternatively spliced isoforms; in these cases, the longest isoforms are shown. For MAP1 proteins, heavy chains are represented. The projection domains are the residues that extend at the surface of MTs. 


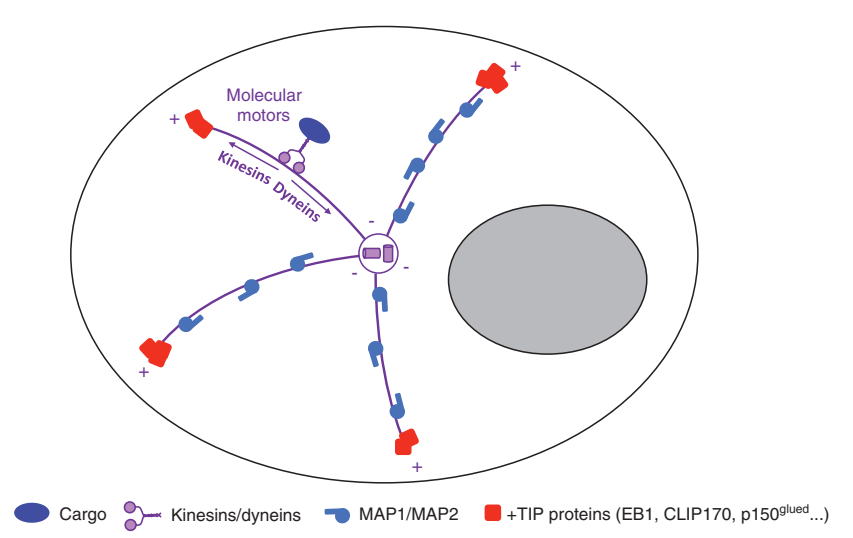

Figure 2: Organization of the MT network and expected localization of MAPs.

MAP1 and MAP2 proteins typically bind along the length of MTs, whereas + TIPs localize at the growing plus end of MTs. Molecular motors move along the length of MTs, with kinesin powering transport towards plus ends, and dynein mediating retrograde transport towards the MTOC.

targeting proteins (- TIPs) have also recently been identified and shown to be involved in the control of minus-end MT dynamics (31).

End-binding proteins (EB) constitute a highly conserved + TIP family, present from yeasts to humans, that localize to spindle and cytoplasmic MTs, and regulate their dynamics and organization $(32,33)$. In mammalian cells, the three MT end-binding proteins, EB1, EB2 and EB3, share substantial sequence homology, but while EB1 and EB3 promote MT growth by suppressing catastrophe, EB2 does not play a direct role in MT dynamic instability $(34,35)$. Recent work has proposed that EB2 plays an essential role in the regulation of focal adhesion dynamics and cell migration via its interaction with the kinase MAP4K4 (36). EB3 is expressed preferentially in the central nervous system and muscle, while EB1 is ubiquitously expressed (37). The C-terminal domain of EB proteins promotes several + TIP interactions, and acts as a hub that organizes and maintains + TIP networks (38). In particular, EB1 interacts with components of the dynactin complex, the activator for cytoplasmic dynein: $\mathrm{p} 150^{\text {glued }}$ (DCTN1, described below), p50/dynamitin (DCTN2), and the intermediate chain of dynein (39). EB proteins have also been shown to interact with several kinesin motor proteins, such as kinesin 8 Kif18B to control microtubular length (40) and kinesin Kif17 to stabilize MTs by posttranslational acetylation (41).

Cytoskeleton-associated proteins (CAP) rich in glycine residues (CAP-Gly proteins) constitute another + TIP family whose members interact with both MTs and EB proteins. Prominent examples are CLIP proteins and the large subunit of the dynactin complex p150 ${ }^{\text {glued }}$. CLIP-170 binds specifically at MT plus ends and modulates MT nucleation, polymerization, and transitions from shrinkage to growth (42). CLIP-170 binds to EB1, $\alpha$-tubulin, p150 ${ }^{\text {glued }}$, and recruits various cargos to MT tips, including the dynein-dynactin complex (43), and vesicles (44). Other CLIP proteins include the brain-specific CLIP-115 and CLIPR-59, which does not localized to MTs at steadystate but is associated with the trans-Golgi network and the plasma membrane where it regulates their dynamics. The large subunit of the dynactin complex, p150 glued (DCTN1) is an evolutionarily conserved + TIP protein containing a N-terminal CAP-Gly domain mediating interaction with MT, and two C-terminal coiled-coil regions that are required for dimerization and interaction with the dynein intermediate chain and with dynactin shoulder $(45,46)$. p150 15 glued promotes MT formation in vitro by catalyzing nucleation, increasing polymerization rate, and inhibiting catastrophe (47). The coiled-coil $\alpha$-helical domain CC1B of $150^{\text {glued }}$ is necessary for its ability to enhance dynein processivity (48). Its overexpression as transdominant uncouples dynein-based transport, and is often used as a tool to demonstrate dependency of viral transport on dynein.

Proteins rich in basic, serine and proline (basic-Ser/ Pro) sequences constitute the largest and most diverse family of + TIPs. Prominent examples are the adenomatous polyposis coli (APC) tumor suppressor, and the spectraplakins microtubule-actin crosslinking factor (MACF) and bullous pemphigoid antigen 1 (BPAG1, dystonin). They possess a small four-residue motif, Ser-x-Ile-Pro (SxIP, where $\mathrm{x}$ denotes any amino acid), which is specifically recognized by the EBH domain of EB proteins (49). Dystonin is a giant protein that can interact with all three elements of the cytoskeleton, intermediate filaments, actin and MTs, via a N-terminal actin-binding domain and a C-terminal MT-binding domain (50). Four major isoforms (Dystonin a, b, e and $\mathrm{n}$ ) have been identified to date, with differential tissue expression and resulting from alternative splicing patterns.

Proteins with TOG domains include the CLIPassociated proteins (CLASPs) that were initially characterized through their ability to bind to CLIP-170, CLIP-115 and MTs, and to co-localize with the CLIPs at MT distal ends (51). CLASP1 is ubiquitously expressed, while CLASP2 is more abundant in the brain. CLASP1 and CLASP2 promote MT rescue and inhibit catastrophes $(52,53)$.

Finally, WD40-repeats proteins are characterized by the presence of repeating units of 44-60 variable residues that end with tryptophan (W) and aspartate (D) dipeptides (54). In the last decade, multiple WD40 protein complexes have been identified, which generally 
function as rigid platforms for protein-protein and protein-DNA interactions and are involved in diverse range of cellular processes, such as signal transduction, gene transcriptional regulation, protein modifications, cytoskeleton assembly, vesicular trafficking, DNA damage and repair, cell death and control of cell division (55). Lis1 is a + TIP member of WD40-repeat protein family enriched in neurons whose insufficiency following heterozygous mutations in the Lis1 gene causes lissencephaly, a severe brain malformation due to abnormal neuronal migration during brain development (56). Lis1 interacts with motors and other + TIP proteins, and regulates MT organization, and dynein/dynactin binding to MTs and cargo (57-59).

\section{Role of non-motile MAPs in intracellular trafficking}

Although motors are the molecular complexes that mediate cargo intracellular trafficking, evidence also supports a direct role for MAPs in cargo movement along microtubular tracks. MAPs bind along the length of MTs, differing in their distribution and in the domains that project from the surface of the MT. Post-translational modifications of both MAPs and tubulin are key in regulating their interactions as well as MT dynamics and stability. Phosphorylation of MAPs can either favor binding to assembled MTs, as in the case of MAP1 proteins, or lead to loss of binding, as is seen with MAP2, tau, and MAP4 (60-62). In addition, tubulin undergoes a wide range of post-translation modifications $(63,64)$, that lead to the existence of different populations of MTs within cells, with detyrosinated and acetylated MTs representing a small subset of stable, non-growing MTs.

It is thought that MAPs can regulate trafficking firstly by serving as adaptor proteins that specify motor and cargo identity within the complex set of proteins that constitute motor-cargo interactions (65). Moreover, depending on their projection domains, MAPs can act as selective obstacles to motor-MT attachment, decreasing both the frequency of productive encounters and the average length of runs, or on the contrary enhance affinity of motors to MTs (66-69). It is thought that the differential regulation of motor attachment to MT by MAPs allows them to modulate movement directionality to achieve compartimentalized and polarized transport (67, 70-72). As the role of MAPs in intracellular transport becomes increasingly clear, so also our understanding of how viruses divert these mechanisms to promote their trafficking within cells.

\section{Promotion of viral trafficking by MAPs}

Viruses are obligate parasites that encode a limited number of genes, and require complementing host cell functions for replication and spread. Importantly, once viruses enter cells they require cytoplasmic transport to reach specific subcellular sites for replication and egress. Numerous studies have revealed that retrograde and anterograde transport of animal viruses is supported by MTs and their associated proteins $(14,15,73,74)$, and an increasing number of viral proteins that interact with MTs or MAPs have begun to be identified (Table 1). Virus-MAP interactions, be they functional or physical, can promote virus trafficking in an infected cell, by directly facilitating latching on of virus particles to cytoskeletal tracks, or modifying MT dynamics to optimize movement along the tracks.

\section{MAPs facilitate interaction of viruses with microtubules}

HIV-1 has been shown to use actin microfilaments for short-range transport at the cell and nuclear periphery, and MT motors for long-range intracellular movement (10, 75, 76). Confusingly, numerous non-motile tubulin- and actin-associated proteins have been identified by genomewide screens of proteins thought to contribute to efficient HIV-1 infection (77-79). However, as HIV interacts with the cytoskeleton at multiple points in its replication cycle and remodels the cytoskeleton to promote viral replication, it is unclear which cellular factors are specifically involved in trafficking. Our group reported the interaction of HIV-1 capsids with human MAP1A (see Figure 3) and MAP1S, involving MAP1 light chain LC2. Depletion of MAP1A or MAP1S in primary human macrophages disrupted HIV-1 infection by hampering efficient trafficking of incoming HIV-1 complexes to the nucleus, and reduced the association of HIV-1 capsids with both dynamic and stable MTs, suggesting that MAP1 proteins help tether incoming viral capsids to the microtubular network, thus promoting cytoplasmic trafficking (80). In addition, a role for MAP4 was reported in the early steps of HIV-1 infection. Depletion of MAP4 was shown to impact HIV-1 reverse transcription but not nuclear translocation (81). However, it is currently unknown whether or not MAP4 directly interacts with viral proteins.

Adenovirus (Ad) uses MT-directed transport and dynein to reach the centrosomes and nuclear pores 
Table 1: Structural MAPs and + TIPs interact with several different viruses.

\begin{tabular}{|c|c|c|c|c|}
\hline MAP family & Examples & Virus interaction & Role of MAP-virus interaction & References \\
\hline \multirow[t]{5}{*}{ MAP1/2 } & MAP1A & HIV-1 p24 capsid & Promote HIV-1 capsid transport & $(80)$ \\
\hline & MAP1B & RSV NS1 and NS2 & Contribute to the STAT2-degrading activity of NS2 & (104) \\
\hline & MAP1S & HIV-1 p24 capsid & Promote HIV-1 capsid transport & $(80)$ \\
\hline & $\mathrm{LC} 3$ & HIV-1 Vif & Inhibit autophagy & $(108)$ \\
\hline & MAP4 & HIV-1 & Promote HIV-1 reverse transcription & $(81)$ \\
\hline \multirow[t]{13}{*}{+ TIPs } & EB1 & HIV-1 & Induce microtubule stabilization & (91) \\
\hline & & HSV-1 & Promote HSV-1 transport & (86) \\
\hline & & HIV-1 Vpr & Alter phagosome movement and maturation & $(107)$ \\
\hline & CLIP-170 & HSV-1 & Promote HSV-1 transport & $(86)$ \\
\hline & p150 glued & HIV-1 & Promote HIV-1 capsid transport & (10) \\
\hline & & Adenovirus & Promote Ad capsid transport & (87) \\
\hline & & HSV & Promote HSV-1 capsid transport & $(88,89)$ \\
\hline & & HIV-1 Vpr & Alter phagosome movement and maturation & (107) \\
\hline & CLASP1 & HSV-1 & Induce microtubule stabilization, virus spread & (97) \\
\hline & CLASP2 & HSV-1 & Induce microtubule stabilization, virus spread & (97) \\
\hline & Lis1 & Poliovirus $3 \mathrm{~A}$ & Membrane protein trafficking & (102) \\
\hline & & HIV-1 Tat & Contribute to microtubule formation & (103) \\
\hline & Dystonin & HSV-1 & Promote HSV-1 capsid transport & $(85,100)$ \\
\hline
\end{tabular}

The table lists reported functional and physical interactions between viruses and MAPs, and their effect on viral infection.
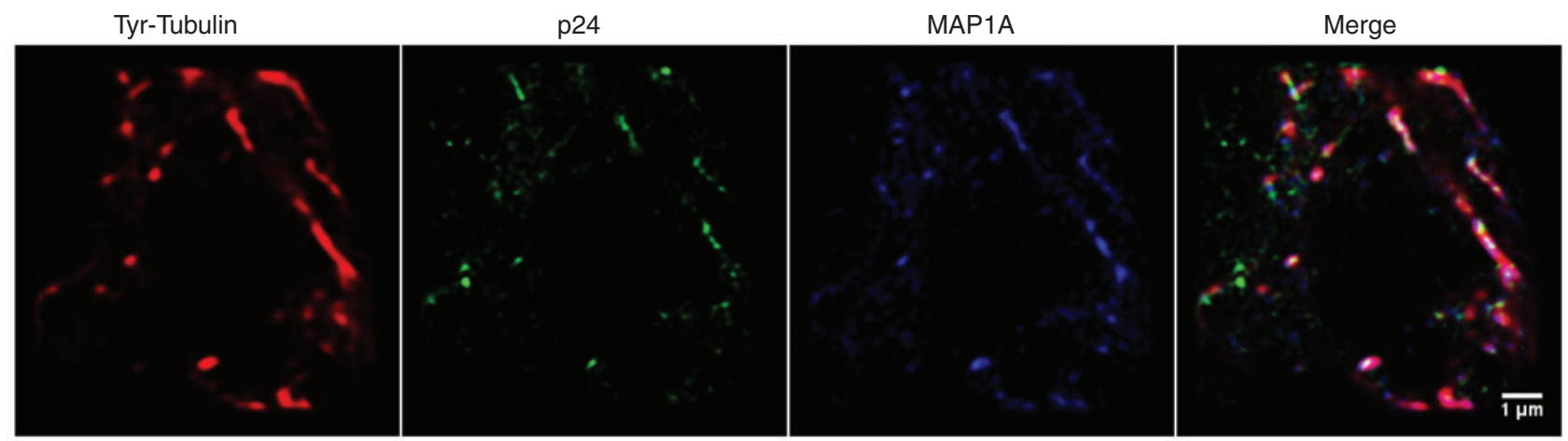

Figure 3: MAP1A interacts with HIV-1 capsid.

Super resolution images of HIV-1 infected HeLa cells were acquired by BioAxial's Conical Diffraction Microscopy (CODIM) (111) at $4 \mathrm{~h}$ postinfection. Cells were labeled with anti-tyrosinated (Tyr)-tubulin (red), anti-capsid p24 (green) and anti-MAP1A (blue) antibodies. Scale bar represents $1 \mu \mathrm{m}$.

rapidly following receptor-mediated endocytosis. MAPs have been shown to enhance binding of Ad capsid to MTs, although the motor protein dynein seems to be largely responsible for this interaction and for promoting Ad trafficking $(82,83)$.

In the case of herpes simplex virus type 1 (HSV-1), recent work identifies the MT plus end dystonin/BPAG1 protein as a binding partner of the tegument protein pUL37, which controls the movement of capsids within the cytosol (84). In dystonin-depleted cells, HSV-1 capsids could reach the centrosome of fibroblasts but the transport of capsids away from the centrosome towards the nucleus was significantly blocked, indicating a defect in the polarity switch of viral transport occurring at the centrosome (85). This work was the first to illustrate how non-motile MAPs can regulate the directionality of transport along MTs. Moreover, initiation of capsid transport soon after cell entry requires a + TIP complex comprising CLIP-170, EB1 and dynactin 1. In the absence CLIP-170, viral capsids remained at the cell periphery, unable to reach the nucleus (86).

Finally, the dynein co-factor CAP-gly protein p150 glued has been implicated in the infection of several viruses. Overexpression of a transdominant inhibitor of p150 $0^{\text {glued }}$ inhibited HIV-1 and Ad trafficking to the nucleus and inhibited infection $(10,87)$. Moreover, the herpesvirus 
tegument protein VP1/2 interacts with $150^{\text {glued }}$, and inhibition of dynactin blocks cytoplasmic HSV-1 transport along MTs $(88,89)$.

\section{MAPs mediate virus-induced microtubule stabilization}

Besides interacting with MAPs to latch onto the MT network, viruses can promote their trafficking in infected cells by enhancing MT stability. Several viruses induce MT rearrangements and tubulin acetylation to varying extents, and in some cases, evidence suggests that stable MTs may be important for infection. However, the underlying mechanisms by which many viruses remodel host MT networks and potential roles for MAPs still remain relatively poorly understood. Recent work showed that adenovirus, African swine fever virus (ASFV), influenza A virus, reoviruses, HSV-1, HIV-1, and Ebola virus all induce MT stabilization, often observed with concomitant posttranslational modifications such as acetylation and detyrosination in host cells (90-96). Specifically, HSV-1 is thought to promote both its trafficking to the nucleus and its egress by multiple mechanisms, including the stabilization and hyperacetylation of MTs by the tegument protein VP22 (94) and viral kinase Us2 (97), binding of the molecular chaperone Hsp90 (98), disruption of the centrosomal nature of the MT-organizing center (MTOC) and its transfer to the trans-Golgi network $(97,99,100)$. In this context, cytoplasmic linker-associated proteins (CLASPs), which are specialized + TIPs that control MT formation at the trans-Golgi network, were found to be specifically required for virus-induced MT stabilization and HSV-1 spread (97). Furthermore, initial engagement of HSV-1 particles onto MTs involves a + TIP complex comprising EB1, CLIP-170, and dynactin-1 (DCTN1) to initiate retrograde transport in infected cells (86).

HIV-1 infection was also shown to induce tubulin post-translational modifications that are associated with the formation of a more stable subset of MTs, thus facilitating translocation of HIV-1 across the cytoplasm (80, 91). Virus-induced MT stabilization, which occurs very rapidly after cell entry (within 1-2 h post-infection), was found to involve EB1 (91) and, albeit to a lesser extent, MAP1A/MAP1S proteins (80). Conversely, HIV-1 infection was impaired by overexpression of moesin, a member of the ezrin, radixin and moesin (ERM) family that negatively regulates the stable MT network (101), thus confirming that MT stabilization favors viral particle trafficking to their site of replication. Together, these findings illustrate how viruses have evolved to target specialized + TIPs and other MAPs to control MT stability and promote early postentry stages of infection.

\section{Conclusion}

For their transport inside infected cells, viruses rely both on cytoskeletal filaments and their associated motor proteins to travel from their site of entry to their site of replication, assembly and egress, with speed and efficiency to avoid rapid overpowering by the cell's innate immunity and degradation machineries. Although some viral proteins have been shown to interact directly with molecular motors, evidence shows that viruses also depend on interactions with actin/tubulin binding proteins for efficient trafficking. The study of MAPs and how they promote viral trafficking is key to better understand the complexities of virus movement within infected cells, in particular to address how directionality of transport and switching between filaments are regulated to reach precise points of destination.

In many published reports, an ambiguity remains whether the interaction of viral proteins with non-motile MAPs can directly affect trafficking or whether motor proteins are inevitably involved. This is particularly true of studies where the implicated MAP is part of a greater motor complex. Moreover, some studies remain inconclusive as to whether virus-MAP interactions that stabilize MTs lead to enhanced infection by specifically affecting viral trafficking, or rather by affecting general transport. For instance, the poliovirus $3 \mathrm{~A}$ protein was shown to bind to Lis1 and disrupt protein trafficking, but this was found to impact the cell surface expression of short-lived receptors, including those for tumor necrosis factor and interferon (IFN), rather than viral particle trafficking per se (102). Moreover, it has been reported that HIV-1 Tat also binds to Lis1 and this interaction might contribute to the effect of Tat on MT formation (103). Further work is undoubtedly warranted to clarify the specific implication of MAPs in viral replication.

It is interesting to note that beyond promoting virus trafficking in the infected cell, interaction of MAPs with viral proteins can impact other cellular functions regulated by MTs such as mitosis, apoptosis, and immunity, and thus contribute to virus-associated pathologies. Human respiratory syncytial virus (RSV), a major cause of severe respiratory diseases, efficiently suppresses cellular innate immunity, using its two unique non-structural proteins, NS1 and NS2. The two NS proteins suppress both type I IFN induction and the IFN response pathways by interfering with various innate immunity actors such as RIG-I and 
STAT2. Recently, MAP1B was shown to interact with NS1 and NS2 and to contribute to the STAT2-degrading activity of NS2 (104). In the case of HIV infection, the viral transactivator Tat protein has been shown to contribute to neuronal damage observed in the brain of HIV-1 patients with neurological dysfunctions, by causing rapid proteasomemediated degradation of MAP2 leading to the collapse of cytoskeletal filaments, as well as aberrant splicing of tau $(105,106)$. MAP proteins have also been linked to cellular processes such as phagocytosis and autophagy, which are both repressed in HIV-1 target cells, macrophages and T lymphocytes, respectively. Two HIV-1 proteins were recently shown to play an inhibitory role in these processes: Vpr was shown to interact with EB1 and p150"lued, perturbing their MT plus end localization, thus altering phagosome movement and maturation (107), while Vif was shown to interact directly with LC3B, a major autophagy component (108). In this context, the study of MAP1S will prove an interesting topic, since MAP1S is involved both in autophagy, regulating autophagosomal biogenesis and degradation, and interacting with autophagosome-associated LC3 of MAP1A and MAP1B (109), and in bacterial phagocytosis by macrophages through interaction with MyD88 a key adaptor of Toll-like receptors (110).

The implication of MAPs and MTs in viral disease is a fascinating area of research that is only just emerging and will no doubt generate many interesting studies in the coming years.

Acknowledgements: We thank Sébastien Nisole for the graphic design of Figures.

Funding: This work was supported by grants from the Agence Nationale de Recherche sur le SIDA (ANRS) and an ATIP-Avenir grant to N.J.A. Bioaxial SAS, a private company that develops high resolution imaging instruments, employed D.M.P and R.P, and N.J.A is employed by the Centre National de Recherche Scientifique (CNRS).

\section{References}

1. Desai A, Mitchison TJ. Microtubule polymerization dynamics. Annu Rev Cell Dev Biol 1997; 13: 83-117.

2. Brandenburg B, Zhuang X. Virus trafficking - learning from single-virus tracking. Nat Rev Microbiol 2007; 5: 197-208.

3. Greber UF, Fassati A. Nuclear import of viral DNA genomes. Traffic 2003; 4: 136-43.

4. Greber UF, Way M. A superhighway to virus infection. Cell 2006; 124: 741-54.

5. Marsh M, Helenius A. Virus entry: open sesame. Cell 2006; 124: 729-40.
6. Radtke K, Dohner K, Sodeik B. Viral interactions with the cytoskeleton: a hitchhiker's guide to the cell. Cell Microbiol 2006; 8: 387-400.

7. Leopold PL, Pfister KK. Viral strategies for intracellular trafficking: motors and microtubules. Traffic 2006; 7: 516-23.

8. Suomalainen M, Nakano MY, Keller S, Boucke K, Stidwill RP, Greber UF. Microtubule-dependent plus- and minus end-directed motilities are competing processes for nuclear targeting of adenovirus. J Cell Biol 1999; 144: 657-72.

9. Leopold PL, Kreitzer G, Miyazawa N, Rempel S, Pfister KK, Rodriguez-Boulan E, Crystal RG. Dynein- and microtubulemediated translocation of adenovirus serotype 5 occurs after endosomal lysis. Hum Gene Ther 2000; 11: 151-65.

10. Arhel N, Genovesio A, Kim KA, Miko S, Perret E, Olivo-Marin JC, Shorte S, Charneau P. Quantitative four-dimensional tracking of cytoplasmic and nuclear HIV-1 complexes. Nat Methods 2006; 3: 817-24.

11. McDonald D, Vodicka MA, Lucero G, Svitkina TM, Borisy GG, Emerman M, Hope TJ. Visualization of the intracellular behavior of HIV in living cells. J Cell Biol 2002; 159: 441-52.

12. Wolfstein A, Nagel CH, Radtke K, Dohner K, Allan VJ, Sodeik B. The inner tegument promotes herpes simplex virus capsid motility along microtubules in vitro. Traffic 2006; 7 : 227-37.

13. Radtke K, Kieneke D, Wolfstein A, Michael K, Steffen W, Scholz T, Karger A, Sodeik B. Plus- and minus-end directed microtubule motors bind simultaneously to herpes simplex virus capsids using different inner tegument structures. PLoS Pathog 2010; 6: e1000991.

14. Dodding MP, Way M. Coupling viruses to dynein and kinesin-1. EMBO J 2011; 30: 3527-39.

15. Gaudin R, de Alencar BC, Arhel N, Benaroch P. HIV trafficking in host cells: motors wanted! Trends Cell Biol 2013; 23: 652-62.

16. Halpain S, Dehmelt L. The MAP1 family of microtubuleassociated proteins. Genome Biol 2006; 7: 224-30.

17. Villarroel-Campos D, Gonzalez-Billault C. The MAP1B case: an old MAP that is new again. Dev Neurobiol 2014; 74: 953-71.

18. Mei X, Sweatt AJ, Hammarback JA. Regulation of microtubuleassociated protein 1B (MAP1B) subunit composition. J Neurosci Res 2000; 62: 56-64.

19. Mann SS, Hammarback JA. Molecular characterization of light chain 3. J Biol Chem 1994; 269: 11492-7.

20. Pedrotti B, Colombo R, Isla K. Microtubule associated protein MAPI $A$ is an actin-binding and crosslinking protein. Cell Motil Cytoskeleton 1994; 29: 110-6.

21. Tögel M, Wiche G, Propst F. Novel features of the light chain of microtubule-associated protein MAP1B: microtubule stabilization, self interaction, actin filament binding, and regulation by the heavy chain. J Cell Biol 1998; 143: 695-707.

22. Montenegro-Venegas C, Tortosa E, Rosso S, Peretti D, Bollati F, Bisbal M, Jausoro I, Avila J, Cáceres A, Gonzalez-Billault C. MAP1B regulates axonal development by modulating RhoGTPase Rac1 activity. Mol Biol Cell 2010; 21: 3518-28.

23. Dehmelt L, Halpain S. The MAP2/Tau family of microtubuleassociated proteins. Genome Biology 2004; 6: 204-13.

24. Trinczek B, Ebneth A, Mandelkow EM, Mandelkow E. Tau regulates the attachment/detachment but not the speed of motors in microtubule-dependent transport of single vesicles and organelles. J Cell Sci 1999; 112: 2355-67. 
25. Ebneth A, Godemann R, Stamer K, Illenberger S, Trinczek B, Mandelkow E. Overexpression of tau protein inhibits kinesindependent trafficking of vesicles, mitochondria, and endoplasmic reticulum: implications for Alzheimer's disease. J Cell Biol 1998; 143: 777-94.

26. Bulinski JC, McGraw TE, Gruber D, Nguyen HL, Sheetz MP. Overexpression of MAP4 inhibits organelle motility and trafficking in vivo. J Cell Sci 1997; 110: 3055-64.

27. Olson KR, McIntosh JR, Olmsted JB. Analysis of MAP 4 function in living cells using green fluorescent protein (GFP) chimeras. J Cell Biol 1995; 130: 639-50.

28. Akhmanova A, Steinmetz MO. Tracking the ends: a dynamic protein network controls the fate of microtubule tips. Nat Rev Mol Cell Biol 2008; 9: 309-22.

29. Akhmanova A, Steinmetz MO. Microtubule + TIPs at a glance. J Cell Sci 2010; 123(Pt 20): 3415-9.

30. Perez F, Diamantopoulos GS, Stalder R, Kreis TE. CLIP170 highlights growing microtubule ends in vivo. Cell 1999; 96: 517-27.

31. Akhmanova A, Hoogenraad CC. Microtubule minus-endtargeting proteins. Curr Biol 2015; 25: R162-71.

32. Berrueta L, Kraeft SK, Tirnauer JS, Schuyler SC, Chen LB, Hill DE, Pellman D, Bierer BE. The adenomatous polyposis coli-binding protein EB1 is associated with cytoplasmic and spindle microtubules. Proc Natl Acad Sci USA 1998; 95: 10596-601.

33. Morrison EE, Wardleworth BN, Askham JM, Markham AF, Meredith DM. EB1, a protein which interacts with the APC tumour suppressor, is associated with the microtubule cytoskeleton throughout the cell cycle. Oncogene 1998; 17: 3471-7.

34. Komarova Y, De Groot CO, Grigoriev I, Gouveia SM, Munteanu EL, Schober JM, Honnappa S, Buey RM, Hoogenraad CC, Dogterom M, Borisy GG, Steinmetz MO, Akhmanova A. Mammalian end binding proteins control persistent microtubule growth. J Cell Biol 2009; 184: 691-706.

35. Komarova Y, Lansbergen G, Galjart N, Grosveld F, Borisy GG, Akhmanova A. EB1 and EB3 control CLIP dissociation from the ends of growing microtubules. Mol Biol Cell 2005; 16: 5334-45.

36. Yue J, Xie M, Gou X, Lee P, Schneider MD, Wu X. Microtubules regulate focal adhesion dynamics through MAP4K4. Dev Cell 2014; 31: 572-85.

37. Nakagawa H, Koyama K, Murata Y, Morito M, Akiyama T, Nakamura Y. EB3, a novel member of the EB1 family preferentially expressed in the central nervous system, binds to a CNS-specific APC homologue. Oncogene 2000; 19: 210-6.

38. Lansbergen G, Akhmanova A. Microtubule plus end: a hub of cellular activities. Traffic 2006; 7: 499-507.

39. Berrueta L, Tirnauer JS, Schuyler SC, Pellman D, Bierer BE. The APC-associated protein EB1 associates with components of the dynactin complex and cytoplasmic dynein intermediate chain. Curr Biol 1999; 9: 425-8.

40. Stout JR, Yount AL, Powers JA, Leblanc C, Ems-McClung SC, Walczak CE. Kif18B interacts with EB1 and controls astral microtubule length during mitosis. Mol Biol Cell 2011; 22: 3070-80.

41. Jaulin F, Kreitzer G. KIF17 stabilizes microtubules and contributes to epithelial morphogenesis by acting at MT plus ends with EB1 and APC. J Cell Biol 2010; 190: 443-60.

42. Arnal I, Heichette C, Diamantopoulos GS, Chretien D. CLIP-170/ tubulin-curved oligomers coassemble at microtubule ends and promote rescues. Curr Biol 2004; 14: 2086-95.
43. Lansbergen G, Komarova Y, Modesti M, Wyman C, Hoogenraad CC, Goodson HV, Lemaitre RP. Conformational changes in CLIP170 regulate its binding to microtubules and dynactin localization. J Cell Biol 2004; 166: 1003-14.

44. Pierre P, Scheel J, Rickard JE, Kreis TE. CLIP-1 70 links endocytic vesicles to microtubules. Cell 1992; 70: 887-900.

45. Vaughan KT, Valee RB. Cytoplasmic dynein binds dynactin through a direct interaction between the intermediate chains and p150 glued. J Cell Biol 1995; 131: 1507-16.

46. King SJ, Brown CL, Maier KC, Quintyne NJ, Schroer TA. Analysis of the dynein-dynactin interaction in vitro and in vivo. Mol Biol Cell 2003; 14: 5089-97.

47. Lazarus JE, Moughamian AJ, Tokito MK, Holzbaur EL. Dynactin subunit $\mathrm{p} 150$ (Glued) is a neuron-specific anti-catastrophe factor. PLoS Biol 2013; 11: e1001611.

48. Tripathy SK, Weil SJ, Chen C, Anand P, Vallee RB, Gross SP. Autoregulatory mechanism for dynactin control of processive and diffusive dynein transport. Nat Cell Biol 2014; 16: 1192-201.

49. Honnappa S, Gouveia SM, Weisbrich A, Damberger FF, Bhavesh NS, Jawhari H, Grigoriev I, van Rijssel FJ, Buey RM, Lawera A, Jelesarov I, Winkler FK, Wüthrich K, Akhmanova A, Steinmetz MO. An EB1-binding motif acts as a microtubule tip localization signal. Cell 2009; 138: 366-76.

50. Young KG, Kothary R. Dystonin/Bpag1-a link to what? Cell Motil Cytoskeleton 2007; 64: 897-905.

51. Akhmanova A, Hoogenraad CC, Drabek K, Stepanova T, Dortland B, Verkerk T, Vermeulen W, Burgering BM, De Zeeuw Cl, Grosveld F, Galjart N. CLASPs are CLIP-115 and -170 associating proteins involved in the regional regulation of microtubule dynamics in motile fibroblasts. Cell 2001; 104: 923-35.

52. Al-Bassam J, Kim H, Brouhard G, van Oijen A, Harrison SC, Chang F. CLASP promotes microtubule rescue by recruiting tubulin dimers to the microtubule. Dev Cell 2010; 19: 245-58.

53. Mimori-Kiyosue Y, Grigoriev I, Lansbergen G, Sasaki H, Matsui C, Severin F, Galjart N, Grosveld F, Vorobjev I, Tsukita S, Akhmanova A. CLASP1 and CLASP2 bind to EB1 and regulate microtubule plus-end dynamics at the cell cortex. J Cell Biol 2005; 168: 141-53.

54. Suganuma T, Pattenden SG, Workman JL. Diverse functions of WD40 repeat proteins in histone recognition. Genes Dev 2008; 22: $1265-8$.

55. Zhang $C$, Zhang $F$. The multifunctions of WD40 proteins in genome integrity and cell cycle progression. J Genomics 2015; 3: 40-50.

56. Leventer RJ, Pilz DT, Matsumoto N, Ledbetter DH, Dobyns WB. Lissencephaly and subcortical band heterotopia: molecular basis and diagnosis. Mol Med Today 2000; 6: 277-84.

57. Smith DS, Niethammer M, Ayala R, Zhou Y, Gambello MJ, Wynshaw-Boris A, Tsai LH. Regulation of cytoplasmic dynein behaviour and microtubule organization by mammalian Lis1. Nat Cell Biol 2000; 2: 767-75.

58. Sapir T, Elbaum M, Reiner O. Reduction of microtubule catastrophe events by LIS1, platelet-activating factor acetylhydrolase subunit. EMBO J 1997; 16: 6977-84.

59. Coquelle FM, Caspi M, Cordelières FP, Dompierre JP, Dujardin DL, Koifman C, Martin P, Hoogenraad CC, Akhmanova A, Galjart N, De Mey JR, Reiner O. LIS1, CLIP-170's Key to the dynein/dynactin pathway. Mol Cell Biol 2002; 22: 3089-102.

60. Diaz-Nido J, Armas-Portela R, Avila J. Addition of protease inhibitors to culture medium of neuroblastoma cells induces both neu- 
rite outgrowth and phosphorylation of microtubule-associated protein MAP-1B. J Cell Sci 1991; 98(Pt 3): 409-14.

61. Mandelkow EM, Biernat J, Drewes G, Gustke N, Trinczek B, Mandelkow E. Tau domains, phosphorylation, and interactions with microtubules. Neurobiol Aging 1995; 16: 355-63.

62. Illenberger S, Drewes G, Trinczek B, Biernat J, Meyer HE, Olmsted JB, Mandelkow EM, Mandelkow E. Phosphorylation of microtubule-associated proteins MAP2 and MAP4 by the protein kinase p110mark. J Biol Chem 1996; 271: 10834-43.

63. Janke C, Bulinski JC. Post-translational regulation of the microtubule cytoskeleton: mechanisms and functions. Nat Rev Mol Cell Biol 2011; 12: 773-86.

64. Song Y, Brady ST. Post-translational modifications of tubulin: pathways to functional diversity of microtubules. Trends Cell Biol 2015; 25: 125-36.

65. Akhmanova A, Hammer JA, 3rd. Linking molecular motors to membrane cargo. Curr Opin Cell Biol 2010; 22: 479-87.

66. Metzger T, Gache V, Xu M, Cadot B, Folker ES, Richardson BE, Gomes ER, Baylies MK. MAP and kinesin-dependent nuclear positioning is required for skeletal muscle function. Nature 2012; 484: 120-4.

67. Atherton J, Houdusse A, Moores C. MAPping out distribution routes for kinesin couriers. Biol Cell 2013; 105: 465-87.

68. Lopez LA, Sheetz MP. Steric inhibition of cytoplasmic dynein and kinesin motility by MAP2. Cell Motil Cytoskeleton 1993; 24: 1-16.

69. Hagiwara H, Yorifuji H, Sato-Yoshitake R, Hirokawa N. Competition between motor molecules (kinesin and cytoplasmic dynein) and fibrous microtubule-associated proteins in binding to microtubules. J Biol Chem 1994; 269: 3581-9.

70. Lipka J, Kapitein LC, Jaworski J, Hoogenraad CC. Microtubulebinding protein doublecortin-like kinase 1 (DCLK1) guides kinesin-3-mediated cargo transport to dendrites. EMBO J 2016; 35: 302-18.

71. Semenova I, Ikeda K, Resaul K, Kraikivski P, Aguiar M, Gygi S, Zaliapin I, Cowan A, Rodionov V. Regulation of microtubulebased transport by MAP4. Mol Biol Cell 2014; 25: 3119-32.

72. Jolly AL, Gelfand VI. Bidirectional intracellular transport: utility and mechanism. Biochem Soc Trans 2011; 39: 1126-30.

73. Ploubidou A, Way M. Viral transport and the cytoskeleton. Curr Opin Cell Biol 2001; 13: 97-105.

74. Merino-Gracia J, Garcia-Mayoral MF, Rodriguez-Crespo I. The association of viral proteins with host cell dynein components during virus infection. FEBS I 2011; 278: 2997-3011.

75. Campbell EM, Hope TJ. Gene therapy progress and prospects: viral trafficking during infection. Gene Ther 2005; 12: 1353-9.

76. Naghavi MH, Goff SP. Retroviral proteins that interact with the host cell cytoskeleton. Curr Opin Immunol 2007; 19: 402-7.

77. Brass AL, Dykxhoorn DM, Benita Y, Yan N, Engelman A, Xavier RJ, Lieberman J, Elledge SJ. Identification of host proteins required for HIV infection through a functional genomic screen. Science 2008; 319: 921-6.

78. König R, Zhou Y, Elleder D, Diamond TL, Bonamy GM, Irelan JT, Chiang CY, Tu BP, De Jesus PD, Lilley CE, Seidel S, Opaluch AM, Caldwell JS, Weitzman MD, Kuhen KL, Bandyopadhyay S, Ideker T, Orth AP, Miraglia LJ, Bushman FD, Young JA, Chanda SK. Global analysis of host-pathogen interactions that regulate early-stage HIV-1 replication. Cell 2008; 135: 49-60.

79. Zhou H, Xu M, Huang Q, Gates AT, Zhang XD, Castle JC, Stec E, Ferrer M, Strulovici B, Hazuda DJ, Espeseth AS. Genome-scale
RNAi screen for host factors required for HIV replication. Cell Host Microbe 2008; 4: 495-504.

80. Fernandez J, Portilho DM, Danckaert A, Munier S, Becker A, Roux P, Zambo A, Shorte S, Jacob Y, Vidalain PO, Charneau P, Clavel F, Arhel NJ. Microtubule-associated proteins 1 (MAP1) promote human immunodeficiency virus type I (HIV-1) intracytoplasmic routing to the nucleus. J Biol Chem 2015; 290: 4631-46.

81. Gallo DE, Hope TJ. Knockdown of MAP4 and DNAL1 produces a post-fusion and pre-nuclear translocation impairment in HIV-1 replication. Virology 2012; 422: 13-21.

82. Kelkar SA, Pfister KK, Crystal RG, Leopold PL. Cytoplasmic dynein mediates adenovirus binding to microtubules. J Virol 2004; 78: 10122-32.

83. Bremner KH, Scherer J, Yi J, Vershinin M, Gross SP, Vallee RB. Adenovirus transport via direct interaction of cytoplasmic dynein with the viral capsid hexon subunit. Cell Host Microbe 2009; 6: 523-35.

84. Pasdeloup D, McElwee M, Beilstein F, Labetoulle M, Rixon FJ. Herpesvirus tegument protein pUL37 interacts with dystonin/ BPAG1 to promote capsid transport on microtubules during egress. J Virol 2013; 87: 2857-67.

85. McElwee M, Beilstein F, Labetoulle M, Rixon FJ, Pasdeloup D. Dystonin/BPAG1 promotes plus-end-directed transport of herpes simplex virus 1 capsids on microtubules during entry. J Virol 2013; 87: 11008-18.

86. Jovasevic V, Naghavi MH, Walsh D. Microtubule plus end-associated CLIP-170 initiates HSV-1 retrograde transport in primary human cells. J Cell Biol 2015; 211: 323-37.

87. Engelke MF, Burckhardt CJ, Morf MK, Greber UF. The dynactin complex enhances the speed of microtubule-dependent motions of adenovirus both towards and away from the nucleus. Viruses 2011; 3: 233-53.

88. Zaichick SV, Bohannon KP, Hughes A, Sollars PJ, Pickard GE, Smith GA. The herpesvirus VP1/2 protein is an effector of dynein-mediated capsid transport and neuroinvasion. Cell Host Microbe 2013; 13: 193-203.

89. Döhner K, Wolfstein A, Prank U, Echeverri C, Dujardin D, Vallee R, Sodeik $B$. Function of dynein and dynactin in herpes simplex virus capsid transport. Mol Biol Cell 2002; 13: 2795-809.

90. Husain M, Harrod KS. Enhanced acetylation of alpha-tubulin in influenza A virus infected epithelial cells. FEBS Lett 2011; 585: 128-32.

91. Sabo Y, Walsh D, Barry DS, Tinaztepe S, de Los Santos K, Goff SP, Gundersen GG, Naghavi MH. HIV-1 induces the formation of stable microtubules to enhance early infection. Cell Host Microbe 2013; 14: 535-46.

92. Jouvenet N, Monaghan P, Way M, Wileman T. Transport of African swine fever virus from assembly sites to the plasma membrane is dependent on microtubules and conventional kinesin. J Virol 2004; 78: 7990-8001.

93. Warren JC, Rutkowski A, Cassimeris L. Infection with replicationdeficient adenovirus induces changes in the dynamic instability of host cell microtubules. Mol Biol Cell 2006; 17: 3557-68.

94. Elliott $\mathrm{G}, \mathrm{O}$ 'hare P. Herpes simplex virus type 1 tegument protein VP22 induces the stabilization and hyperacetylation of microtubules. J Virol 1998; 72: 6448-55.

95. Parker JSL, Broering TJ, Kim J, Higgins DE, Nibert ML. Reovirus core protein 2 determines the filamentous morphology of viral 
inclusion bodies by interacting with and stabilizing microtubules. J Virol 2002; 76: 4483-96.

96. Ruthel G, Demmin GL, Kallstrom G, Javid MP, Badie SS, Will AB, Nelle T, Schokman R, Nguyen TL, Carra JH, Bavari S, Aman MJ. Association of ebola virus matrix protein VP40 with microtubules. J Virol 2005; 79: 4709-19.

97. Naghavi MH, Gundersen GG, Walshc D. Plus-end tracking proteins, CLASPs, and a viral Akt mimic regulate herpesvirusinduced stable microtubule formation and virus spread. Proc Natl Acad Sci USA 2013; 110: 18268-73.

98. Zhong M, Zheng K, Chen M, Xiang Y, Jin F, Ma K, Qiu X, Wang Q, Peng T, Kitazato K, Wang Y. Heat-shock protein 90 promotes nuclear transport of herpes simplex virus 1 capsid protein by interacting with acetylated tubulin. PLoS One 2014; 9: e99425.

99. Kotsakis A, Pomeranz LE, Blouin A, Blaho JA. Microtubule reorganization during herpes simplex virus type 1 Infection facilitates the nuclear localization of VP22, a major virion tegument protein. J Virol 2001; 75: 8697-711.

100. Pasdeloup D, Labetoulle M, Rixon FJ. Differing effects of herpes simplex virus 1 and pseudorabies virus infections on centrosomal function. J Virol 2013; 87: 7102-12.

101. Naghavi MH, Valente S, Hatziioannou T, de Los Santos K, Wen Y, Mott C, Gundersen GG, Goff SP. Moesin regulates stable microtubule formation and limits retroviral infection in cultured cells. EMBO J 2007; 26: 41-52.

102. Kondratova AA, Neznanov N, Kondratov RV, Gudkov AV. Poliovirus protein $3 \mathrm{~A}$ binds and inactivates LIS1, causing block of membrane protein trafficking and deregulation of cell division. Cell Cycle 2005; 4: 1403-10.

103. Epie N, Ammosova T, Sapir T, Voloshin Y, Lane WS, Turner W, Reiner O, Nekhai S. HIV-1 Tat interacts with LIS1 protein. Retrovirology 2005; 2: 6.

104. Swedan S, Andrews J, Majumdar T, Musiyenko A, Barik S. Multiple functional domains and complexes of the two nonstructural proteins of human respiratory syncytial virus contribute to interferon suppression and cellular location. J Virol 2011; 85: 10090-100.

105. Aprea S, Del Valle L, Mameli G, Sawaya BE, Khalili K, Peruzzi F. Tubulin-mediated binding of human immunodeficiency virus-1 Tat to the cytoskeleton causes proteasomal-dependent degradation of microtubule-associated protein 2 and neuronal damage. J Neurosci 2006; 26: 4054-62.

106. Kadri F, Pacifici M, Wilk A, Parker-Struckhoff A, Del Valle L, Hauser KF, Knapp PE, Parsons C, Jeansonne D, Lassak A, Peruzzi F. HIV-1-Tat protein inhibits SC35-mediated Tau exon 10 inclusion through up-regulation of DYRK1A kinase. J Biol Chem 2015; 290: 30931-46.

107. Dumas A, Lê-Bury G, Marie-Anaïs F, Herit F, Mazzolini J, Guilbert T, Bourdoncle P, Russell DG, Benichou S, Zahraoui A, Niedergang F. The HIV-1 protein Vpr impairs phagosome maturation by controlling microtubule-dependent trafficking. J Cell Biol 2015; 211: 359-72.

108. Borel S, Robert-Hebmann V, Alfaisal J, Jain A, Faure M, Espert L, Chaloin L, Paillart JC, Johansen T, Biard-Piechaczyk M. HIV-1 viral infectivity factor interacts with microtubule-associated protein light chain 3 and inhibits autophagy. AIDS 2015; 29: 275-86.

109. Xie R, Wang F, McKeehan WL, Liu L. Autophagy enhanced by microtubule- and mitochondrion-associated MAP1S suppresses genome instability and hepatocarcinogenesis. Cancer Res 2011; 71: 7537-46.

110. Shi M, Zhang Y, Liu L, Zhang T, Han F, Cleveland J, Wang F, McKeehan WL, Li Y, Zhang D. MAP1S protein regulates the phagocytosis of bacteria and toll-like receptor (TLR) signaling. J Biol Chem 2016; 291: 1243-50.

111. Caron J, Fallet C, Tinevez JY, Moisan L, Braitbart LP, Sirat GY, Shorte SL. Conical diffraction illumination opens the way for low phototoxicity super-resolution imaging. Cell Adh Migr 2014; 8: 430-9. 